\title{
Mitochondrial oxidative stress contributes differently to rat pancreatic islet cell apoptosis and insulin secretory defects after prolonged culture in a low non-stimulating glucose concentration
}

\author{
L. P. Roma $\cdot$ S. M. Pascal • J. Duprez • J.-C. Jonas
}

Received: 25 November 2011 / Accepted: 19 April 2012 /Published online: 29 May 2012

(C) Springer-Verlag 2012

\begin{abstract}
Aims/hypothesis Pancreatic beta cells chronically exposed to low glucose concentrations show signs of oxidative stress, loss of glucose-stimulated insulin secretion (GSIS) and increased apoptosis. Our aim was to confirm the role of mitochondrial oxidative stress in rat islet cell apoptosis under these culture conditions and to evaluate whether its reduction similarly improves survival and GSIS.

Methods Apoptosis, oxidative stress-response gene mRNA expression and glucose-induced stimulation of mitochondrial metabolism, intracellular $\mathrm{Ca}^{2+}$ concentration and insulin secretion were measured in male Wistar rat islets cultured for 1 week in RPMI medium containing $5-10 \mathrm{mmol} / \mathrm{l}$ glucose with or without manganese(III) tetrakis(4-benzoic acid)porphyrin (MnTBAP) or $\mathrm{N}$-acetyl-L-cysteine (NAC). Oxidative stress was measured in islet cell clusters cultured under similar conditions using cytosolic and mitochondrial redox-sensitive green fluorescent protein (roGFP1/mt-roGFP1).

Results Prolonged culture in $5 \mathrm{vs} 10 \mathrm{mmol} / \mathrm{l}$ glucose increased mt-roGFP1 (but not roGFP1) oxidation followed by beta cell apoptosis and loss of GSIS resulting from
\end{abstract}

L. P. Roma and S. M. Pascal contributed equally to this study.

Electronic supplementary material The online version of this article (doi:10.1007/s00125-012-2581-6) contains peer-reviewed but unedited supplementary material, which is available to authorised users.

L. P. Roma · S. M. Pascal · J. Duprez · J.-C. Jonas $(\bowtie)$

Université catholique de Louvain, Institut de recherche

expérimentale et clinique, Pôle d'endocrinologie, diabète et nutrition,

Avenue Hippocrate 55, B1.55.06,

1200 Brussels, Belgium

e-mail: jean-christophe.jonas@uclouvain.be reduced insulin content, mitochondrial metabolism, $\mathrm{Ca}^{2+}$ influx and $\mathrm{Ca}^{2+}$-induced secretion. Tolbutamide-induced, but not high $\mathrm{K}^{+}$-induced, $\mathrm{Ca}^{2+}$ influx was also suppressed. Under these conditions, MnTBAP, but not NAC, triggered parallel $\sim 50-70 \%$ reductions in mt-roGFP1 oxidation and beta cell apoptosis, but failed to protect against the loss of GSIS despite significant improvement in glucose-induced and tolbutamide-induced $\mathrm{Ca}^{2+}$ influx.

Conclusions/interpretation Mitochondrial oxidative stress contributes differently to rat pancreatic islet cell apoptosis and insulin secretory defects during culture in a low glucose concentration. Thus, targeting beta cell survival may not be sufficient to restore insulin secretion when beta cells suffer from prolonged mitochondrial oxidative stress, e.g. in the context of reduced glucose metabolism.

Keywords Apoptosis · c-Myc $\cdot$ Catalytic antioxidant Cytosolic calcium concentration $\cdot$ Haem oxygenase 1 . Insulin secretion - Low glucose concentration . Metallothionein - Mitochondria $\cdot$ MnTBAP $\cdot$ Oxidative stress $\cdot$ Pancreatic beta cell $\cdot$ roGFP

$\begin{array}{ll}\text { Abbreviations } \\ {\left[\mathrm{Ca}^{2+}\right]_{\mathrm{i}}} & \begin{array}{l}\text { Intracellular } \mathrm{Ca}^{2+} \text { concentration } \\ \text { DTT }\end{array} \\ \text { GSIS } & \begin{array}{l}\text { Githiothreitol } \\ \text { MnTBAP }\end{array} \\ & \begin{array}{l}\text { Manganese(III)tetrakis } \\ \text { (4-benzoic acid)porphyrin }\end{array} \\ \text { mt-roGFP } & \begin{array}{l}\text { Mitochondrial redox-sensitive green } \\ \text { fluorescent protein }\end{array} \\ \text { NAC } & \begin{array}{l}N \text {-Acetyl-L-cysteine } \\ \text { roGFP }\end{array} \\ \text { ROS } & \begin{array}{l}\text { Redox-sensitive green fluorescent protein } \\ \text { Reactive oxygen species }\end{array}\end{array}$

Abbreviations

$\left[\mathrm{Ca}^{2+}\right]_{\mathrm{i}} \quad$ Intracellular $\mathrm{Ca}^{2+}$ concentration

DTT Dithiothreitol

GSIS Glucose-stimulated insulin secretion

(4-benzoic acid)porphyrin

Mitochondrial redox-sensitive green

roGFP Redox-sensitive green fluorescent protein

Reactive oxygen species 


\section{Introduction}

The acute glucose regulation of insulin secretion and proinsulin biosynthesis by pancreatic beta cells plays a critical role in glucose homeostasis. In the long term, however, beta cells also adapt their mass and secretory capacity to prolonged changes in insulin demand, i.e. during prolonged alterations in food supply or under pathophysiological conditions associated with insulin resistance (reviewed by Hinke et al [1] and Karaca et al [2]). For instance, prolonged fasting in rodents reduces islet mRNA and protein expression of genes enriched in beta cells such as preproinsulin, glucose transporter-2, glucokinase and voltage-dependent $\mathrm{Ca}^{2+}$ channels, with concomitant reduction in glucosestimulated insulin secretion (GSIS), and subsequent feeding of the animals corrects these alterations within 1 day [3-5]. Similar alterations in gene expression have been observed in native beta cells of rats implanted with an insulinoma, together with a marked reduction in beta cell mass due to cell atrophy and apoptosis $[4,6]$.

Also in vitro, rodent beta cell glucose responsiveness and survival are optimally preserved in medium containing $10 \mathrm{mmol} / 1$ glucose. Thus, culture of isolated rat islets or purified beta cells in the presence of 2,3 or $5 \mathrm{mmol} / \mathrm{l}$ glucose, i.e. at glucose concentrations lower than the threshold concentration for in vitro stimulation of insulin secretion, markedly altered the expression of genes enriched in beta cells and the ability of beta cells to secrete insulin in response to glucose $[7,8]$ while increasing their apoptosis $[9$, 10]. The latter effect has been attributed to (1) decreased mitochondrial ATP production with rise in AMP concentrations and consequent activation of AMP-activated protein kinase [11], (2) decreased protein synthesis and consequent activation of an intrinsic mitochondrial apoptotic programme [12], (3) increased mRNA and protein levels of the proapoptotic transcription factor c-MYC [13], and (4) increased oxidative stress with subsequent activation of c-Jun N-terminal kinase $[14,15]$ (reviewed by Martens et al [16]). The role of oxidative stress is supported by observations that beta cell apoptosis is preceded by increased expression of integrated stress-response and oxidative stress-response genes [8] and that its stimulation by culture in low glucose is significantly reduced by the free radical scavenger, $N$-acetylL-cysteine (NAC), and by manganese(III)tetrakis(4-benzoic acid)porphyrin (MnTBAP) [14, 15], a superoxide dismutase mimetic, catalase mimetic and peroxynitrite scavenger that also increases the expression of the antioxidant and antiapoptotic enzyme, haem oxygenase $1[17,18]$. However, the possible link between increased oxidative stress and loss of beta cell glucose responsiveness under these culture conditions has not been thoroughly investigated. Because of the possible relevance of this model to other conditions under which beta cell glucose metabolism is reduced after exposure to various types of stress [16], we tested the effects of MnTBAP and NAC on alterations in beta cell glucose responsiveness in rat islets cultured for 1 week in a low nonstimulating concentration of glucose.

\section{Methods}

Materials Diazoxide, sodium azide, dithiothreitol (DTT) and tolbutamide were from Sigma (St Louis, MO, USA). MnTBAP was from Alexis Biochemicals (Lausen, Germany), and NAC was from Merck (Darmstadt, Germany).

Adenoviruses Adenoviruses encoding redox-sensitive green fluorescent protein (roGFP1) and mitochondria-targeted mtroGFP1 were generated and amplified using the pAdEasy system (Stratagene, La Jolla, CA, USA), as described (electronic supplementary material [ESM] Methods) [19].

Islet isolation and culture Islets from $\sim 200 \mathrm{~g}$ male Wistar rats were obtained by collagenase digestion of the pancreas followed by density gradient centrifugation [20]. They were cultured for a week at $37^{\circ} \mathrm{C}$ and $5 \% \mathrm{CO}_{2}$ in serum-free RPMI 1640 medium (Invitrogen, Carlsbad, CA, USA) containing $5 \mathrm{~g} / \mathrm{l} \mathrm{BSA}, 5$ or $10 \mathrm{mmol} / \mathrm{l}$ glucose (G5, G10) and various antioxidants. The medium was renewed every other day. All experiments were approved by the local ethics committee for animal experimentation (UCL/MD/2009/009).

Gene mRNA levels Islet total RNA was extracted and reverse transcribed as described previously [21] using RevertAid Reverse Transcriptase and Ribolock RNase inhibitor (Fermentas, Burlington, ON, Canada). Real-time PCR was performed with an iCycler (Bio-Rad, Hercules, CA, USA). For primer sequences and reaction conditions, see ESM Table 1. Gene to Tbp (encoding TATA-box binding protein) mRNA ratios were computed as $2^{-\left(C_{\text {tgene }}-C_{t T b p}\right)}$ and expressed relative to the ratio in G10-cultured islets.

Cell apoptosis Histone-associated DNA fragments (monoand oligo-nucleosomes) were measured in islet cell cytosolic extracts using the Cell Death Detection ELISA ${ }^{\text {PLUS }}$ kit (Roche Diagnostics GmbH, Mannheim, Germany) [22]. The percentage of apoptotic cells on islet sections was determined by TUNEL using the In Situ Cell Death Detection Kit (Roche Diagnostics) [22].

Mitochondrial and cytosolic GSH/GSSG redox status After islet dissociation using trypsin and gentle pipetting in $\mathrm{Ca}^{2+}$ free medium, cell clusters were plated on glass coverslips 
and cultured with RPMI medium containing G10 and 10\% FBS. After overnight culture, they were infected with roGFP1 or mt-roGFP1 adenovirus $\left(\sim 1.8 \times 10^{6}\right.$ infectious units per dish, multiplicity of infection $\sim 25-50$ ) and further cultured for $24-48 \mathrm{~h}$ in $\mathrm{G} 10$, then $18-24 \mathrm{~h}$ in medium containing G5 or G10 with or without antioxidants. After culture, the coverslip was mounted at the bottom of a $37^{\circ} \mathrm{C}$ temperature-controlled chamber placed on the stage of an inverted microscope equipped with a $\times 40$ objective. Cell clusters were perifused at a flow rate of $\sim 1 \mathrm{ml} / \mathrm{min}$ with a bicarbonate-buffered Krebs solution containing (mmol/l) $\mathrm{NaCl}$ (120), $\mathrm{KCl}$ (4.8), $\mathrm{CaCl}_{2}$ (2.5), $\mathrm{MgCl}_{2}$ (1.2), $\mathrm{NaHCO}_{3}$ (24), $1 \mathrm{~g} / 1$ BSA (fraction V; Roche, Basel, Switzerland), G5 or G10 with or without antioxidants. This solution was continuously gassed with $\mathrm{O}_{2} / \mathrm{CO}_{2}(94: 6)$ to maintain $\mathrm{pH} \sim 7.4$.

Long-term changes in cytosolic and mitochondrial redox potential using roGFP1 were measured as described previously [23]. Briefly, cell fluorescence at $535 \mathrm{~nm}$ was measured during alternate excitation at $400 / 480 \mathrm{~nm}$ every $30 \mathrm{~s}$. After 20 min of perifusion in a medium similar to that used during the last culture period, cells were perifused with $10 \mathrm{mmol} / \mathrm{l} \mathrm{DTT}$ to maximally reduce roGFP1, followed by $1 \mathrm{mmol} / 1 \mathrm{H}_{2} \mathrm{O}_{2}$ to maximally oxidise it. The 400:480 ratios of fluorescence intensities were expressed as a percentage of the difference between the ratio of the maximally reduced and the maximally oxidised forms of roGFP1.

Total glutathione content Total glutathione was measured with the Glutathione Fluorescent Detection Kit (Arbor Assays, Ann Arbor, MI, USA) and normalised for differences in islet protein content (ESM Methods).

Adenine nucleotides After culture, islets were incubated for $30 \mathrm{~min}$ in Krebs medium containing $0.5 \mathrm{mmol} / 1$ glucose, and then incubated for 45 min under various conditions. Samples were processed and adenine nucleotides (ATP and ATP+ADP levels) were measured, as described [24], using the ATP Bioluminescence Assay kit CLS II (Roche Diagnostics).

$N A D(P) H$ levels, mitochondrial membrane potential, intracellular $\mathrm{Ca}^{2+}$ concentration $\left(\left[\mathrm{Ca}^{2+}\right]_{i}\right)$ and insulin secretion After culture, islets were transferred to a $37^{\circ} \mathrm{C}$ temperature-controlled perifusion chamber either immediately for the measurement of $\mathrm{NAD}(\mathrm{P}) \mathrm{H}$ autofluorescence and insulin secretion, after loading for $20 \mathrm{~min}$ with $10 \mu \mathrm{mol} / 1$ rhodamine 123 (Molecular probes, Eugene, OR, USA) to measure the mitochondrial membrane potential, or after loading for $2 \mathrm{~h}$ with fura-PE3 acetoxymethyl ester to measure changes in $\left[\mathrm{Ca}^{2+}\right]_{\mathrm{i}}$. The loading medium was similar to that used during culture except for the omission of NAC during fura-PE3 loading. Islets were then perifused (flow rate $\sim 1 \mathrm{ml} / \mathrm{min}$ ) with a bicarbonate-buffered Krebs solution containing $0.5-20 \mathrm{mmol} / \mathrm{l}$ glucose and various test substances. When the concentration of $\mathrm{KCl}$ was raised to $30 \mathrm{mmol} / \mathrm{l}$, that of $\mathrm{NaCl}$ was reduced to $94.8 \mathrm{mmol} / \mathrm{l}$ to keep the osmolarity unchanged. The acute glucose-induced changes in $\mathrm{NAD}(\mathrm{P}) \mathrm{H}$ levels, mitochondrial membrane potential and $\left[\mathrm{Ca}^{2+}\right]_{\mathrm{i}}$ were recorded by microspectrofluorimetry with Quanticell $700 \mathrm{~m}$ (Visitech, Sunderland, UK) [20]. GSIS was measured by RIA in 2 min effluent collections from 30-110 perifused islets [25]. At the end of perifusion, the islets were disrupted by sonication in $10 \mathrm{mmol} / \mathrm{l}$ Tris, $0.2 \mathrm{mmol} / 1 \mathrm{NaCl}, 10 \mathrm{mmol} / \mathrm{l} \mathrm{EDTA}$, and their insulin and DNA contents were measured [26].

Statistical analysis Results are mean \pm SEM for at least three islet or cell cluster preparations. Statistical significance of differences between groups was assessed by unpaired Student's $t$ test or two-way ANOVA followed by Bonferroni correction. Differences were considered significant if $p<0.05$.

\section{Results}

Effects of MnTBAP on low-glucose-induced oxidative stress and apoptosis in cultured rat islets After 1 week of preculture in G10, further culture of rat islets in G5 vs G10 for 18 $72 \mathrm{~h}$ significantly increased their total glutathione content (in $\mu \mathrm{g} / \mu \mathrm{g}$ protein) from $0.14 \pm 0.01$ in G10 to $0.30 \pm 0.01$ in G5 $(n=3, p<0.001$, unpaired $t$ test). After a few days of culture of islet cell clusters in G10, the roGFP1 fluorescence ratio was higher in the mitochondrial matrix (mt-roGFP1) than in the cytosol (roGFP1) $(p<0.0001$, unpaired $t$ test). Overnight culture in G5 vs G10 induced a significant increase in mtroGFP1 but not in roGFP1 fluorescence ratio (Fig. 1a, c; ESM Fig. 1). Similar changes in mt-roGFP1 oxidation were observed after 3 days of culture (ESM Fig. 2). This increase in mt-roGFP1 oxidation indicates that culture in low glucose increases thiol (probably glutathione) oxidation in the mitochondrial matrix [27]. Accordingly, 1-week culture of rat islets in G5 vs G10 markedly increased the mRNA levels of the oxidative stress-inducible genes, haem oxygenase 1 (Hmoxl), metallothionein 1a (Mt1a) and c-Myc (Fig. 1d-f) without affecting the mRNA levels of the antioxidant enzymes Mn-superoxide dismutase ( $\operatorname{Sod} 2)$ and catalase (ESM Fig. 3). These changes were associated with a large increase in islet DNA fragmentation and in the percentage of TUNEL-positive islet cells (Fig. 1g, h; ESM Fig. 4), but only slightly reduced the proportion of beta cells (measured by immunohistochemistry on islet sections) from $82 \%$ in G10 to $73 \%$ in G5 $(n=2)$. Except for the increase in Hmoxl mRNA levels, the addition of $50 \mu \mathrm{mol} / 1 \mathrm{MnTBAP}$ to the culture medium significantly reduced these alterations by $\sim 50-70 \%$ 


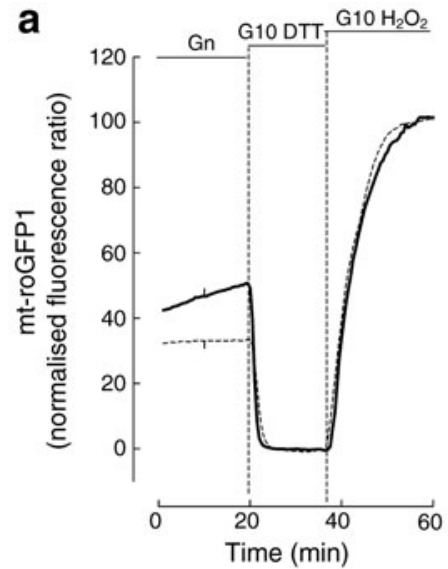

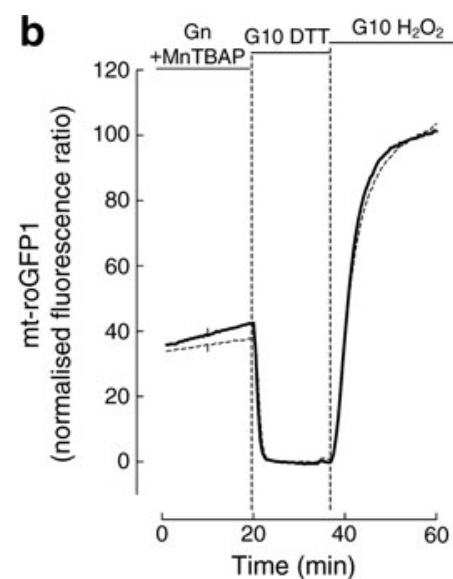
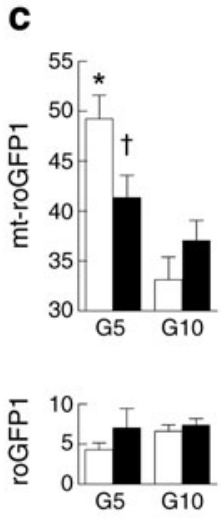
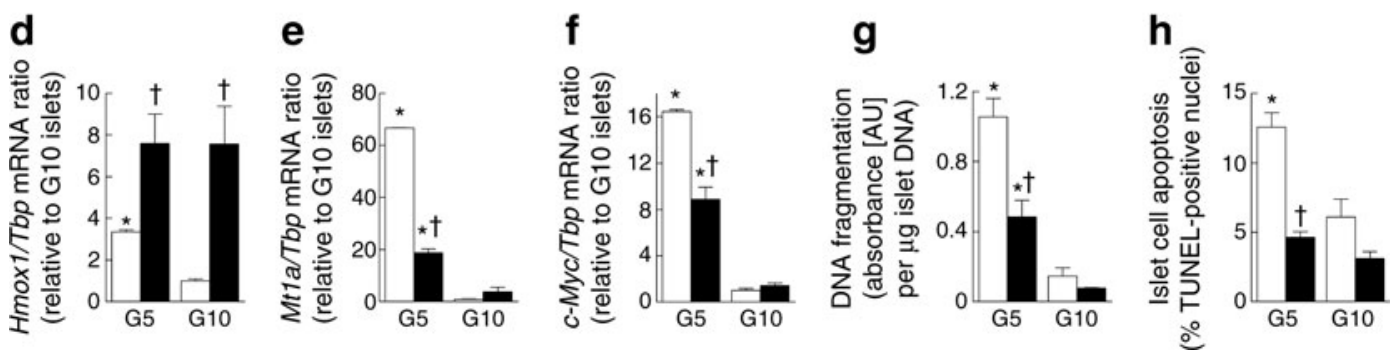

Fig. 1 Effects of MnTBAP on the stimulation of mt-roGFP1 oxidation, islet cell apoptosis and expression of oxidative stress-response genes by 1 week of culture in low glucose. $(\mathbf{a}-\mathbf{c})$ Rat islet cell clusters producing mt-roGFP1 or roGFP1 were cultured overnight in RPMI medium containing $5 \mathrm{mmol} / 1$ glucose (G5, thick traces) or $10 \mathrm{mmol} / \mathrm{l}$ glucose (G10, thin dotted traces) with $10 \%$ FBS in the absence (a, white columns in $\mathbf{c})$ or presence $(\mathbf{b}$, black columns in $\mathbf{c})$ of $50 \mu \mathrm{mol} / 1 \mathrm{MnTBAP}$. (a,b) Ratio of roGFP1 fluorescence intensities (excitation 400/480 nm) was measured during 20 min of perfusion in a medium similar to that used during culture and expressed as a percentage of the difference between the mean ratio measured from 4 to $8 \mathrm{~min}$ after addition of $10 \mathrm{mmol} / \mathrm{l}$ DTT (set at $0 \%$ ) and that measured from 14 to $18 \mathrm{~min}$ after addition of $1 \mathrm{mmol} / 1 \mathrm{H}_{2} \mathrm{O}_{2}$ (set at $100 \%$ ). Mean recordings in clusters producing cytosolic roGFP1 are shown in ESM Fig. 1. (d-h) Rat islets were cultured for 1 week in medium containing 5 or $10 \mathrm{mmol} / 1$ glucose (G5 or G10) and $5 \mathrm{~g} / 1 \mathrm{BSA}$ in the absence (white columns) or presence (black columns) of $50 \mu \mathrm{mol} / 1$ MnTBAP. (d-f) Islet Hmoxl, Mtla and $c-M y c$ to Tbp mRNA ratios are expressed relative to the levels in islets cultured in G10. Data are means \pm SEM for five experiments. (g) Cytosolic histone-associated oligonucleosomes were measured with a commercial ELISA. Data are means \pm SEM for three experiments. (h) Percentage of apoptotic islet cells computed as the ratio TUNEL-positive/DAPI-positive nuclei on islet sections. Results are means \pm SEM for $20-86$ islets in each group. Representative islet sections are shown in ESM Fig. $4 .{ }^{*} p<0.05$ for the effect of glucose (G5 vs G10) by two-way ANOVA + Bonferroni correction or by Student's $t$ test, respectively. $\dagger p<0.05$ for the effect of MnTBAP by two-way ANOVA + Bonferroni correction. AU, arbitrary units; Gn, $n \mathrm{mmol} / \mathrm{l}$ glucose
(Fig. 1). MnTBAP also significantly reduced mt-roGFP1 oxidation in cell clusters cultured for 3 days in G10 (ESM Fig. 2) and tended to reduce islet cell apoptosis after 1 week of culture in G10 (Fig. 1g, h), suggesting its slight beneficial effect under control culture conditions associated with minimal apoptosis [8].

Effects of MnTBAP on the alterations of glucose-stimulated $\left[\mathrm{Ca}^{2+}\right]_{i}$ rise and insulin secretion by prolonged culture in low glucose To test whether oxidative stress contributes to the alterations in beta cell glucose responsiveness after culture in low glucose, we measured glucose-induced changes in $\left[\mathrm{Ca}^{2+}\right]_{\mathrm{i}}$ and insulin secretion in islets cultured for 1 week in medium containing G5 or G10 with or without MnTBAP. After culture in G10, acute glucose stimulation with concentrations from $0.5(\mathrm{G} 0.5)$ to $20(\mathrm{G} 20) \mathrm{mmol} / \mathrm{l}$ induced a transient decrease in $\left[\mathrm{Ca}^{2+}\right]_{\mathrm{i}}$ followed by rapid rises in $\left[\mathrm{Ca}^{2+}\right]_{\mathrm{i}}$ and insulin secretion that were further increased upon islet depolarisation with $30 \mathrm{mmol} / \mathrm{l}$ extracellular $\mathrm{K}^{+}$(K30). In comparison, after 1 week of culture in G5, the islet resting $\left[\mathrm{Ca}^{2+}\right]_{\mathrm{i}}$ was not different, but the glucose-induced $\left[\mathrm{Ca}^{2+}\right]_{\mathrm{i}}$ rise was greatly reduced by $87 \%$, while the $\mathrm{K} 30$ induced $\left[\mathrm{Ca}^{2+}\right]_{\mathrm{i}}$ rise was unaffected (Fig. 2a; Table 1). These alterations, together with the large reduction in islet insulin to DNA content ratio and preproinsulin mRNA levels (Table 3), led to near-complete suppression ( $99 \%$ inhibition) of insulin secretion in response to both stimuli (Fig. 2d; Table 2).

Addition of MnTBAP during culture in G10 did not affect the subsequent acute glucose-induced changes in $\left[\mathrm{Ca}^{2+}\right]_{\mathrm{i}}$ and insulin secretion (Fig. 2b, e; Tables 1 and 2). In contrast, addition of the antioxidant during culture in G5, which tended to increase islet resting $\left[\mathrm{Ca}^{2+}\right]_{\mathrm{i}}$, significantly increased the high-glucose-induced $\left[\mathrm{Ca}^{2+}\right]_{\mathrm{i}}$ rise by approximately fourfold, so that it was only $50-60 \%$ lower than that in islets cultured in 

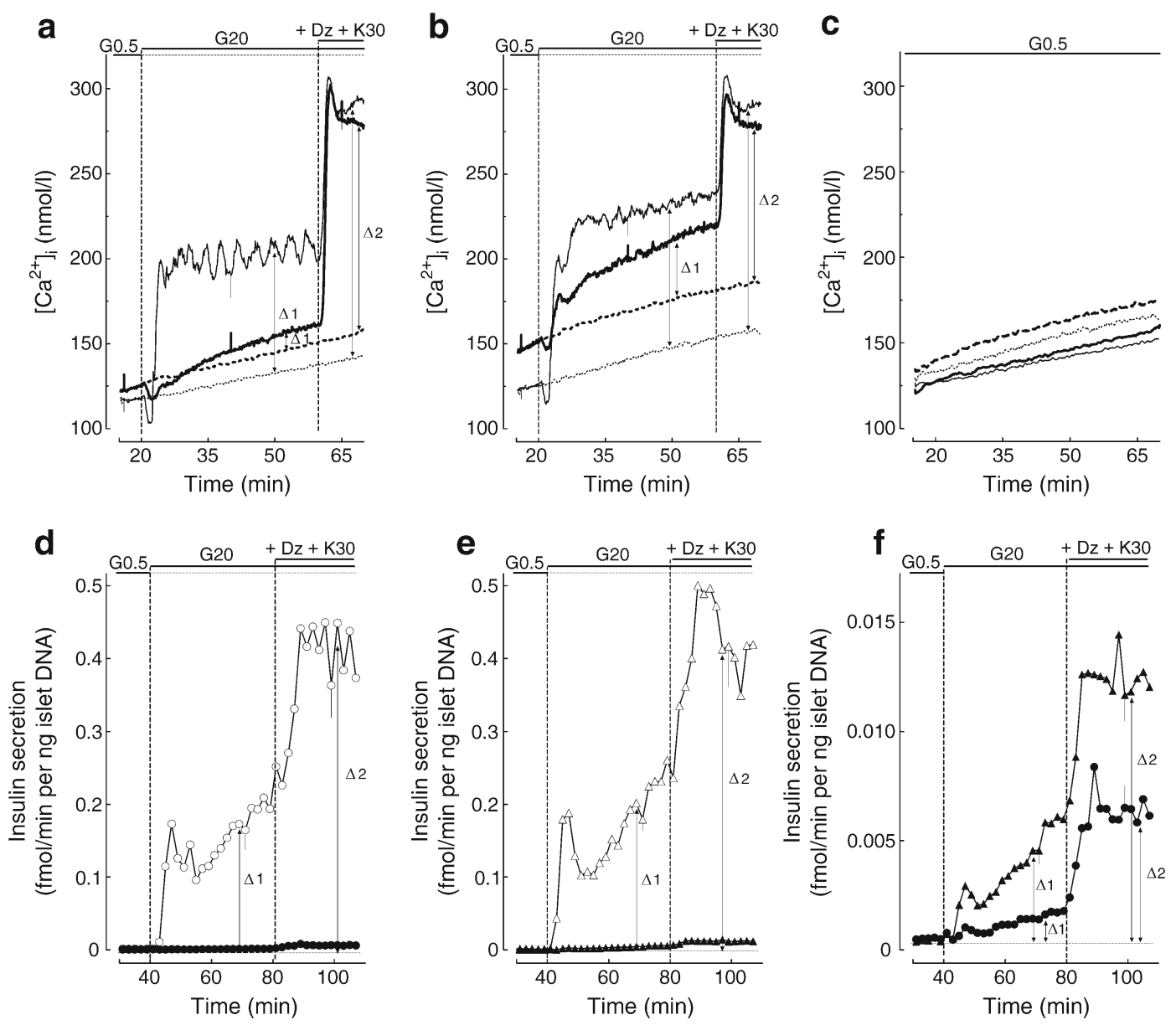

Fig. 2 Effects of MnTBAP on the alterations in glucose-induced $\left[\mathrm{Ca}^{2+}\right]_{\mathrm{i}}$ rise and insulin secretion by 1 week of culture in low glucose. Rat islets were cultured for 1 week in the presence of G5 or G10 without (a, d) or with (b, e) $50 \mu \mathrm{mol} / 1 \mathrm{MnTBAP}$. They were then perifused with a medium containing $0.5 \mathrm{mmol} / \mathrm{l}$ glucose (G0.5) and acutely stimulated from 0.5 to $20 \mathrm{mmol} / \mathrm{l}$ glucose (G0.5 to G20), as indicated on top of the panels (Dz, $250 \mu \mathrm{mol} / \mathrm{l}$ diazoxide; $\mathrm{K} 30,30 \mathrm{mmol} / \mathrm{l}$ extracellular $\mathrm{K}^{+}$concentration). Glucose-induced changes in $\left[\mathrm{Ca}^{2+}\right]_{\mathrm{i}}(\mathbf{a}, \mathbf{b})$ were measured by microspectrofluorimetry and insulin secretion $(\mathbf{d}, \mathbf{e})$ by RIA. Thin traces and white symbols, islet cultured in G10; thick traces and closed symbols, islets

G10 or G10 with MnTBAP (Fig. 2b, Table 1). However, MnTBAP only tended to increase the islet insulin to DNA content ratio and preproinsulin mRNA levels by $\sim 40 \%$ (Table 3). Furthermore, it only slightly increased the insulin secretory response to glucose and $\mathrm{K} 30$ stimulation, so that the acute glucose- and $\mathrm{K} 30$-stimulated insulin secretion remained 97\% lower after a 1-week culture in G5 vs G10 (Fig. 2e, f; Table 2). After normalisation for differences in islet insulin content, however, MnTBAP only tended to improve the insulin secretory response to glucose and no longer improved its stimulation by K30 (Table 2).

Effects of MnTBAP on the alterations in glucose-stimulated mitochondrial metabolism by prolonged culture in low glucose To check whether the beneficial effect of cultured in G5. Dotted traces in (a) and (b) are extrapolations of $\left[\mathrm{Ca}^{2+}\right]_{\mathrm{i}}$ traces obtained in islets perifused in the presence of G0.5 throughout the experiment (c: thin traces, culture in G10; thick traces, culture in G5; continuous traces, culture without MnTBAP; dotted traces, culture with MnTBAP). Insulin secretion data were normalised for differences in islet DNA content. The effect of MnTBAP on insulin secretion after culture in G5 is better shown in (f) where the $y$-axis scale has been expanded (circles, culture without MnTBAP; triangles, culture with MnTBAP). Results are means \pm SEM for eight independent $\left[\mathrm{Ca}^{2+}\right]_{\mathrm{i}}$ experiments (corresponding to 12-13 islets) and for four insulin secretion experiments

MnTBAP on beta cell $\left[\mathrm{Ca}^{2+}\right]_{\mathrm{i}}$ glucose responsiveness after culture in G5 resulted from an increase in glucose metabolism, we next measured the glucose-induced changes in $\mathrm{NAD}(\mathrm{P}) \mathrm{H}$ autofluorescence, rhodamine 123 fluorescence as an indicator of the mitochondrial membrane potential, and adenine nucleotide levels. As expected, acute glucose stimulation from 0.5 to $20 \mathrm{mmol} / \mathrm{l}$ rapidly increased NAD (P)H autofluorescence, hyperpolarised the mitochondrial membrane (as shown by the decrease in rhodamine 123 fluorescence), and increased the ATP/(ATP+ADP) ratio in islets cultured in G10. Addition of $5 \mathrm{mmol} / \mathrm{l}$ azide, which inhibits electron-transport chain complex IV, further increased NAD(P)H autofluorescence while maximally depolarising the mitochondrial membrane and reducing the ATP/ (ATP+ADP) ratio (Fig. 3a, c, e). 
Table 1 Effects of MnTBAP on changes in islet $\left[\mathrm{Ca}^{2+}\right]_{\mathrm{i}}(\mathrm{nmol} / \mathrm{l})$ induced by 1 week of culture in low vs intermediate glucose concentrations

\begin{tabular}{lllll}
\hline $\begin{array}{l}\text { Culture } \\
\text { condition }\end{array}$ & $n$ & \multicolumn{2}{l}{$\left[\mathrm{Ca}^{2+}\right]_{\mathrm{i}}(\mathrm{nmol} / \mathrm{l})$} \\
\cline { 3 - 5 } & & $\mathrm{G} 0.5$ & $\Delta_{1}(\mathrm{G} 0.5-\mathrm{G} 20)$ & $\begin{array}{c}\Delta_{2}(\mathrm{G} 0.5- \\
\mathrm{G} 20 \mathrm{~K} 30 \mathrm{Dz})\end{array}$ \\
\hline G5 & 12 & $123 \pm 10$ & $9 \pm 4^{*}$ & $125 \pm 6$ \\
G5+MnTBAP & 13 & $148 \pm 10$ & $35 \pm 4^{*,}$ & $94 \pm 11^{*}$, \\
G10 & 12 & $117 \pm 7$ & $71 \pm 7$ & $149 \pm 10$ \\
G10+MnTBAP & 13 & $124 \pm 7$ & $85 \pm 9$ & $132 \pm 11$ \\
\hline
\end{tabular}

Results are means \pm SEM for the indicated number of experiments $(n)$ In each experiment illustrated in Fig. 2a,b, we calculated the mean $\left[\mathrm{Ca}^{2+}\right]_{\mathrm{i}}$ during the first $4 \mathrm{~min}$ in $\mathrm{G} 0.5$, the last $20 \mathrm{~min}$ in G20, and the last $5 \mathrm{~min}$ in G20K30Dz. $\Delta_{1}$ and $\Delta_{2}$ show the mean differences between $\left[\mathrm{Ca}^{2+}\right]_{\mathrm{i}}$ measured in the presence of G0.5 (dotted lines in Fig. 2) and G20 or G20K30Dz (solid lines in Fig. 2) in different islets during equivalent periods of perifusion

${ }^{*} p<0.05$ for the effect of glucose (G5 vs G10) and ${ }^{\dagger} p<0.05$ for the effect of MnTBAP by two-way ANOVA + Bonferroni correction

${ }^{\star} p<0.05$ by Student's $t$ test for the effect of MnTBAP

Dz, diazoxide

In comparison with control islets, the effects of glucose on $\mathrm{NAD}(\mathrm{P}) \mathrm{H}$ autofluorescence were significantly smaller in islets cultured in G5, both in absolute values and when

Table 2 Effects of MnTBAP on the alterations in glucose-stimulated insulin secretion after 1 week of culture in low vs intermediate glucose concentrations

\begin{tabular}{|c|c|c|c|c|}
\hline $\begin{array}{l}\text { Culture } \\
\text { condition }\end{array}$ & $n$ & G0.5 & $\Delta_{1}(\mathrm{G} 0.5-\mathrm{G} 20)$ & $\begin{array}{l}\Delta_{2}(\mathrm{G} 0.5- \\
\text { G20K30Dz) }\end{array}$ \\
\hline \multicolumn{5}{|c|}{ Insulin secretion (amol/min per ng islet DNA) } \\
\hline G5 & 4 & $0.53 \pm 0.10$ & $0.76 \pm 0.02 * *$ & $5.77 \pm 1.05^{*}$ \\
\hline G5+MnTBAP & 4 & $0.46 \pm 0.06$ & $3.56 \pm 0.52 * *, \dagger$ & $11.97 \pm 1.23^{* *}, \dagger$ \\
\hline G10 & 4 & $1.39 \pm 0.31$ & $152.1 \pm 20.0$ & $413.0 \pm 55.5$ \\
\hline G10+MnTBAP & 4 & $1.22 \pm 0.38$ & $169.1 \pm 20.2$ & $429.4 \pm 54.7$ \\
\hline \multicolumn{5}{|c|}{ Insulin secretion (\% of insulin content per min) } \\
\hline G5 & 4 & $0.001 \pm 0.0001$ & $0.006 \pm 0.001 * *$ & $0.041 \pm 0.009^{* *}$ \\
\hline G5+MnTBAP & 4 & $0.001 \pm 0.0003$ & $0.012 \pm 0.003 * *$ & $0.039 \pm 0.007 * *$ \\
\hline G10 & 4 & $0.004 \pm 0.001$ & $0.141 \pm 0.011$ & $0.426 \pm 0.049$ \\
\hline G10+MnTBAP & 4 & $0.001 \pm 0.0002$ & $0.156 \pm 0.019$ & $0.454 \pm 0.105$ \\
\hline
\end{tabular}

Results are means \pm SEM for the indicated number of experiments $(n)$ In each experiment illustrated in Fig. 2d,e, we computed the average rate of insulin secretion (both in absolute values and relative to the islet insulin content) during the last $8 \mathrm{~min}$ in G0.5, the last $30 \mathrm{~min}$ in G20, and the last $18 \mathrm{~min}$ in G20K30Dz. $\Delta_{1}$ or $\Delta_{2}$ show the mean increase in insulin secretion between G0.5 and G20 or G20K30Dz

$* * p<0.01$ for the effect of glucose (G5 vs G10) by two-way ANOVA + Bonferroni correction. There was no significant effect of MnTBAP by two-way ANOVA + Bonferroni correction

${ }^{\dagger} p<0.01$ by Student's $t$ test for the effect of MnTBAP

$\mathrm{Dz}$, diazoxide expressed as a percentage of the difference in fluorescence between G0.5 and G20+ azide (Fig. 3a; Table 4). Regarding rhodamine 123 fluorescence in islets previously cultured in G5 vs G10, it was lower and tended to decrease with time following a one-phase exponential decay curve with a $T_{1 / 2}$ of approximately $19 \mathrm{~min}$ (Fig. 3c; Table 5). When this leakage was taken into account, the amplitude of the mitochondrial responses to high glucose were significantly lower than those in islets cultured in G10, whereas the response to azide was not (Table 5). A possible explanation for this leakage can be found in ESM Table 2.

Concerning the ATP/(ATP+ADP) ratio, it was significantly higher in islets cultured in G5 vs G10 after incubation in G0.5 but not after incubation in G20 (Fig. 3e). However, we have previously shown that a granular pool of adenine nucleotide with low ATP/ADP ratio reduces the ATP/ADP ratio measured in freshly isolated vs cultured mouse islets and its increase by glucose [24]. This granular pool thereby precludes direct comparison of the amplitude of glucoseinduced changes in the ATP/(ATP+ADP) ratio between conditions associated with large changes in insulin content, i.e. between islets cultured in G5 vs G10 (Table 3). To circumvent this difficulty, we normalised the ATP/(ATP+ ADP) ratios measured in G0.5 and G20 to that measured in G20+azide. On doing so, the glucose-induced increase in normalised ATP/(ATP+ADP) ratio was significantly lower in islets cultured in G5 vs G10 (Fig. 3f). As shown in Fig. 3b, d-f and Tables 4 and 5, the addition of MnTBAP during culture did not increase the amplitude of the acute metabolic response to glucose in islets cultured in G5.

Effects of MnTBAP on the alterations in tolbutamideinduced $\left[\mathrm{Ca}^{2+}\right]_{i}$ rise by prolonged culture in low glucose As the beneficial effect of MnTBAP on beta cell $\left[\mathrm{Ca}^{2+}\right]_{\mathrm{i}}$ glucose responsiveness after culture in G5 did not result from an improvement in glucose metabolism, we next tested the effect of culture in low glucose with or without MnTBAP on the acute $\left[\mathrm{Ca}^{2+}\right]_{\mathrm{i}}$ response to a maximally effective concentration of tolbutamide, a drug that closes $\mathrm{K}_{\text {ATP }}$ channels. As shown in Fig. 4 and Table 6, 1 week of culture in G5 vs G10 significantly decreased the $\left[\mathrm{Ca}^{2+}\right]_{\mathrm{i}}$ response to tolbutamide by $\sim 75 \%$ without significantly affecting the response to $\mathrm{K} 30$. After culture in the presence of MnTBAP, basal $\left[\mathrm{Ca}^{2+}\right]_{\mathrm{i}}$ was significantly elevated in islets cultured in G5 and to a lesser extent in islets cultured in $\mathrm{G} 10$, and the $\left[\mathrm{Ca}^{2+}\right]_{\mathrm{i}}$ response to tolbutamide was increased to a larger extent in islets cultured in G5 vs G10, so that the absolute amplitude of this $\left[\mathrm{Ca}^{2+}\right]_{\text {i }}$ rise was only $55 \%$ lower in islets cultured in G5 vs G10. When expressed as a percentage of the difference between basal and K30stimulated $\left[\mathrm{Ca}^{2+}\right]_{\mathrm{i}}$, MnTBAP completely prevented the $\sim 65 \%$ reduction in the $\left[\mathrm{Ca}^{2+}\right]_{\mathrm{i}}$ response to tolbutamide induced by culture in G5. 
Table 3 Effects of MnTBAP on the alterations in islet insulin and DNA content, insulin to DNA content ratio, and preproinsulin mRNA levels after 1 week of culture in low vs intermediate glucose concentrations

\begin{tabular}{|c|c|c|c|c|c|}
\hline $\begin{array}{l}\text { Culture } \\
\text { condition }\end{array}$ & $n$ & $\begin{array}{l}\text { Insulin content } \\
\text { (pmol/islet) }\end{array}$ & $\begin{array}{l}\text { DNA content } \\
\text { (ng/islet) }\end{array}$ & $\begin{array}{l}\text { Insulin/DNA content } \\
\text { ratio }(\mathrm{fmol} / \mathrm{ng})\end{array}$ & $\begin{array}{l}\text { Preproinsulin/Tbp mRNA } \\
\text { ratio (relative to G10) }\end{array}$ \\
\hline G5 & $4-5$ & $1.61 \pm 0.21^{* *}$ & $94 \pm 12$ & $18.3 \pm 3.6^{* *}$ & $0.13 \pm 0.01 * *$ \\
\hline G5+MnTBAP & $4-5$ & $2.29 \pm 0.26^{* *}$ & $90 \pm 6$ & $25.5 \pm 1.8$ & $0.20 \pm 0.03 * *$ \\
\hline G10 & $4-5$ & $5.73 \pm 1.07$ & $102 \pm 12$ & $61.1 \pm 15.7$ & $1.00 \pm 0.01$ \\
\hline G10+MnTBAP & $4-5$ & $5.20 \pm 0.73$ & $106 \pm 21$ & $50.7 \pm 3.3$ & $0.76 \pm 0.13^{\dagger}$ \\
\hline
\end{tabular}

Results are means \pm SEM for the indicated number of experiments $(n)$

Islet DNA and insulin content were measured at the end of each experiment illustrated in Fig. 2d-f. Insulin/Tbp mRNA ratios were measured by real-time RT-PCR and normalised to the mean ratio for conditions G5 plus G10 within each experiment before being expressed relative to the levels in islets cultured in G10

${ }^{* *} p<0.01$ for the effect of glucose (G5 vs G10) and ${ }^{\dagger} p<0.05$ for the effect of MnTBAP by two-way ANOVA + Bonferroni correction

Effects of NAC alone or in combination with MnTBAP on the alterations in islet cell survival and function after culture in low glucose Because MnTBAP did not fully reduce the stimulation of mt-roGFP1 oxidation, oxidative stressresponse gene expression and islet cell apoptosis by culture in G5, we also tested the efficacy of the $\mathrm{H}_{2} \mathrm{O}_{2}$ scavenger NAC. As shown in ESM Fig. 5a-e, addition of $1 \mathrm{mmol} /$ $1 \mathrm{NAC}$ during culture markedly decreased the stimulation of Hmox 1 mRNA by culture in G5 vs G10, but was ineffective against the oxidation of mt-roGFP1 and the stimulation of islet cell apoptosis and $c-M y c$ and Mt1a mRNA expression. Accordingly, $1 \mathrm{mmol} / 1 \mathrm{NAC}$ did not improve the $\mathrm{Ca}^{2+}$ response to acute glucose stimulation in islets cultured in G5 (ESM Fig. 5f, g). When used at $10 \mathrm{mmol} / \mathrm{l}$, NAC significantly decreased Mt1a mRNA levels, but also increased mt-roGFP1 oxidation and islet cell apoptosis in G5 without improving the $\mathrm{Ca}^{2+}$ response to acute glucose stimulation in islets cultured in G5 (ESM Fig. 5h).

MnTBAP may, at least in part, exert its antioxidant action by increasing superoxide dismutation. We therefore tested whether $\mathrm{H}_{2} \mathrm{O}_{2}$ scavenging with $1 \mathrm{mmol} / \mathrm{l} \mathrm{NAC}$, although ineffective alone, could improve the antioxidant efficacy of MnTBAP. However, in comparison with the effect of MnTBAP alone, the combination of the two agents did not further improve beta cell survival and $\left[\mathrm{Ca}^{2+}\right]_{\mathrm{i}}$ glucose responsiveness after 1 week of culture in G5 (ESM Fig. 6).

\section{Discussion}

This study shows that prolonged culture of rat islets in a non-stimulating glucose concentration rapidly increases mitochondrial glutathione oxidation, followed by beta cell apoptosis and loss of acute GSIS. Under these conditions, the antioxidant, MnTBAP, triggered a parallel $\sim 50 \%$ reduction in both mt-roGFP1 oxidation and beta cell apoptosis, thereby extending previous studies showing a causal link between oxidative stress and islet cell apoptosis during culture in low glucose $[14,15]$. However, despite its antiapoptotic effect, MnTBAP failed to significantly protect against the loss of GSIS, suggesting that the loss of GSIS during prolonged culture in G5 is unrelated to oxidative stress, or that beta cell function is more sensitive than beta cell survival to the level of mitochondrial oxidative stress that persists in the presence of MnTBAP.

Low glucose concentrations increase mitochondrial oxidative stress in rat islet cells The effect of glucose on pancreatic beta cell production of reactive oxygen species (ROS) is controversial, ranging from increased oxidation of ROSsensitive fluorescent dyes by high glucose concentrations [28] to decreased oxidation of the dyes by glucose stimulation [14, 29-31]. The redox-sensitive fluorescent protein roGFP1 does not directly measure ROS production but rather reflects the balance between ROS-dependent oxidation and NADPH-dependent reduction of thiols (glutathione) by a mechanism involving glutaredoxin [23, 27]. Using this probe, we found that lowering the glucose concentration from 10 to $5 \mathrm{mmol} / \mathrm{l}$ for $18 \mathrm{~h}$ increases thiol oxidation in the mitochondrial matrix of dispersed rat islet cells. The increase in mt-roGFP1 fluorescence ratio in G5 is unlikely to have resulted from reduced expression of glutaredoxin without changes in thiol oxidation state, as it also occurs upon acute reduction of glucose from 10 to $2 \mathrm{mmol} / \mathrm{l}$ [19]. The increase in mt-roGFP1 fluorescence ratio may also have resulted from a decrease in mitochondrial glutathione content without changes in mt-roGFP1 oxidation state, but we consider this hypothesis unlikely because islet total glutathione content increased [27] and the mitochondrial and cytosolic concentrations of GSH are similar in other cell types (reviewed by Lash [32]).

After culture in G10, the roGFP1 fluorescence ratio was greater in the mitochondrial matrix than in the cytosol of rat 
Fig. 3 Effects of MnTBAP on the alterations in glucoseinduced changes in mitochondrial metabolism by 1 week of culture in low glucose. After 1 week of culture in G5 or G10 without $(\mathbf{a}, \mathbf{c})$ or with $(\mathbf{b}, \mathbf{d})$ $50 \mu \mathrm{mol} / 1 \mathrm{MnTBAP}, \mathrm{NAD}(\mathrm{P}) \mathrm{H}$ autofluorescence (a, b), rhodamine 123 fluorescence $(\mathbf{c}, \mathbf{d})$ and adenine nucleotide levels $(\mathbf{e}, \mathbf{f})$ were measured in islets perifused or incubated with a medium containing G0.5 (e, f, white bars), G20 (e, f, hatched bars) and $\mathrm{G} 20+5 \mathrm{mmol} / \mathrm{l}$ sodium azide (e, f, closed bars), or with medium containing G0.5 throughout the experiment (c, d, dotted traces). (a-d) Thin lines, culture in G10; thick lines, culture in G5. The rhodamine 123 fluorescence was expressed as a percentage of the fluorescence measured from the 19th to 20th minute of perifusion (last min of perifusion in G0.5 before the stimulation with G20). Data are means \pm SEM for eight independent $\mathrm{NADP}(\mathrm{H})$ experiments (corresponding to 14 islets), five independent rhodamine 123 experiments

(corresponding to six to ten islets) and 14 batches of ten islets for adenine nucleotide measurements (four independent incubations). $\Delta_{1}$ and $\Delta_{2}$, see Tables 5 and 6. (f) Ratio $\mathrm{ATP} /(\mathrm{ATP}+\mathrm{ADP})$ in (e) was normalised to the ratio measured in islets cultured under the same condition and incubated in the presence of G20 +azide. ${ }^{\ddagger} p<0.0001$ for the acute effect of G20 vs G0.5; * $p<0.05$ and $* * * p<0.001$ for the effect of G5 vs G10 during culture; ${ }^{\dagger \dagger} p<0.001$ for the effect of MnTBAP during culture (twoway ANOVA + Bonferroni correction) a
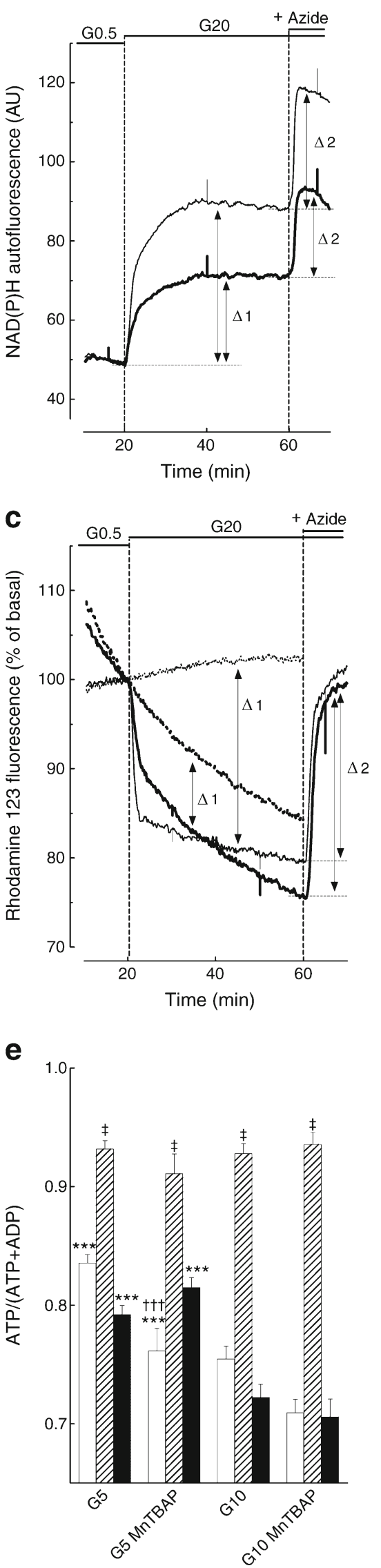

b
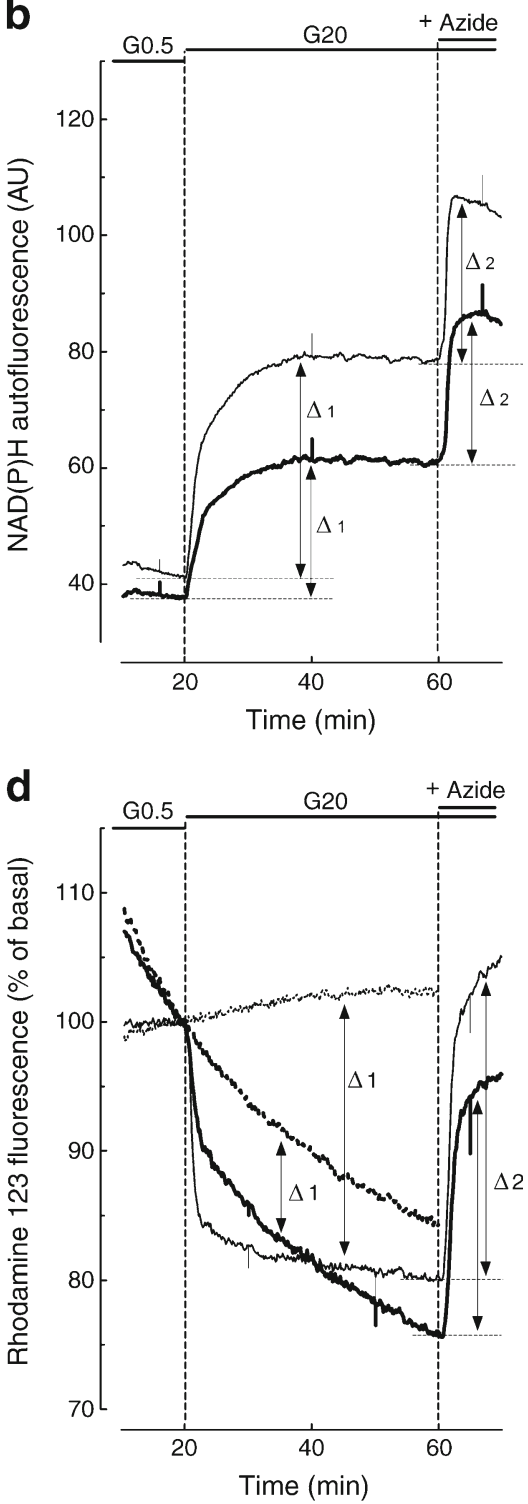

f

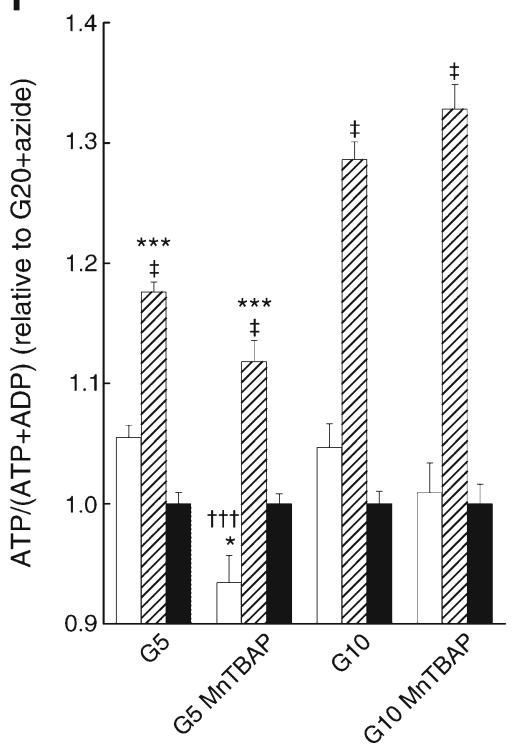


Table 4 Effects of MnTBAP on the alterations in glucose-induced changes in $\mathrm{NAD}(\mathrm{P}) \mathrm{H}$ autofluorescence after 1 week of culture in low vs intermediate glucose concentrations

\begin{tabular}{lllll}
\hline $\begin{array}{l}\text { Culture } \\
\text { condition }\end{array}$ & $n$ & \multicolumn{2}{l}{ Change in NAD(P)H autofluorescence (AU) } \\
\cline { 3 - 5 } & & $\Delta_{1}(\mathrm{G} 0.5-\mathrm{G} 20)$ & $\begin{array}{l}\Delta_{2}(\mathrm{G} 20-\mathrm{G} 20 \\
\text { azide })\end{array}$ & $\Delta_{\mathrm{l}} /\left(\Delta_{1}+\Delta_{2}\right)$ \\
\hline G5 & 14 & $21.6 \pm 2.0^{* *}$ & $20.4 \pm 1.6^{* *}$ & $0.512 \pm 0.015^{* *}$ \\
G5+MnTBAP & 14 & $23.4 \pm 1.4^{* *}$ & $24.4 \pm 1.4$ & $0.489 \pm 0.006^{* *}$ \\
G10 & 14 & $39.8 \pm 2.8$ & $28.3 \pm 1.3$ & $0.579 \pm 0.013$ \\
G10+MnTBAP & 14 & $37.2 \pm 2.0$ & $26.5 \pm 1.3$ & $0.583 \pm 0.007$ \\
\hline
\end{tabular}

Results are means \pm SEM for the indicated number of experiments $(n)$ G0.5 and G20, 0.5 and $20 \mathrm{mmol} / 1$ glucose; azide: $5 \mathrm{mmol} / 1 \mathrm{Na}^{+}$-azide. In each experiment illustrated in Fig. 3a, b, the difference in $\mathrm{NAD}(\mathrm{P}) \mathrm{H}$ autofluorescence between G0.5 and G20 $\left(\Delta_{1}\right)$ and between G20 and G20 azide $\left(\Delta_{2}\right)$ was computed from the average NAD(P)H autofluorescence during the last $5 \mathrm{~min}$ in G0.5, the last $20 \mathrm{~min}$ in G20, and the last $8 \mathrm{~min}$ in $\mathrm{G} 20$ azide

$* * p<0.01$ for the effect of glucose (G5 vs G10) by two-way ANOVA + Bonferroni correction. There was no significant effect of MnTBAP on any of these measurements by two-way ANOVA + Bonferroni correction

$\mathrm{AU}$, arbitrary fluorescence units

islet cells, as reported in cardiomyocytes [33]. The further oxidation of mt-roGFP1 but not roGFP1 after culture in G5 indicates that thiol oxidation at low glucose mainly occurs in the mitochondrial matrix, suggestive of mitochondrial oxidative stress. In agreement, stimulation of dihydroethidine

Table 5 Effects of MnTBAP on the alterations in glucose-induced changes in rhodamine 123 fluorescence after 1 week of culture in low vs intermediate glucose concentrations

Culture condition $n \quad$ Change in rhodamine 123 fluorescence ( $\%$ of basal)

\begin{tabular}{lrll}
\cline { 3 - 4 } & & $\Delta_{1}(\mathrm{G} 0.5-\mathrm{G} 20)$ & $\Delta_{2}(\mathrm{G} 20-\mathrm{G} 20$ azide $)$ \\
\hline G5 & 10 & $-8.6 \pm 1.6^{* * *}$ & $21.1 \pm 4.0$ \\
G5+MnTBAP & 10 & $-8.3 \pm 1.4^{* * *}$ & $17.9 \pm 3.2$ \\
G10 & 6 & $-20.2 \pm 1.9$ & $19.6 \pm 2.0$ \\
G10+MnTBAP & 8 & $-20.3 \pm 1.9$ & $22.2 \pm 3.0$
\end{tabular}

Results are means \pm SEM for the indicated number of experiments $(n)$ G0.5 and G20, 0.5 and $20 \mathrm{mmol} / 1$ glucose; azide: $5 \mathrm{mmol} / 1 \mathrm{Na}^{+}$-azide. In each experiment illustrated in Fig. 3c,d, we computed the mean rhodamine 123 fluorescence from the 23rd to the 60th min, from the 57 th to the 60 th $\mathrm{min}$, and from the $62 \mathrm{nd}$ to the 70 th $\mathrm{min}$ of perifusion. $\Delta_{1}$ shows the mean difference between rhodamine 123 fluorescence during the last $37 \mathrm{~min}$ of perifusion in the presence of G0.5 (dotted lines in Fig. 3) and G20 (solid lines in Fig. 3). $\Delta_{2}$ shows the mean difference in rhodamine 123 fluorescence between the last $3 \mathrm{~min}$ in $\mathrm{G} 20$ and the last $8 \mathrm{~min}$ in $\mathrm{G} 20$ azide

$* * * p<0.001$ for the effect of glucose (G5 vs G10) by two-way ANOVA+Bonferroni correction. There was no significant effect of MnTBAP on any of these measurements by two-way ANOVA + Bonferroni correction
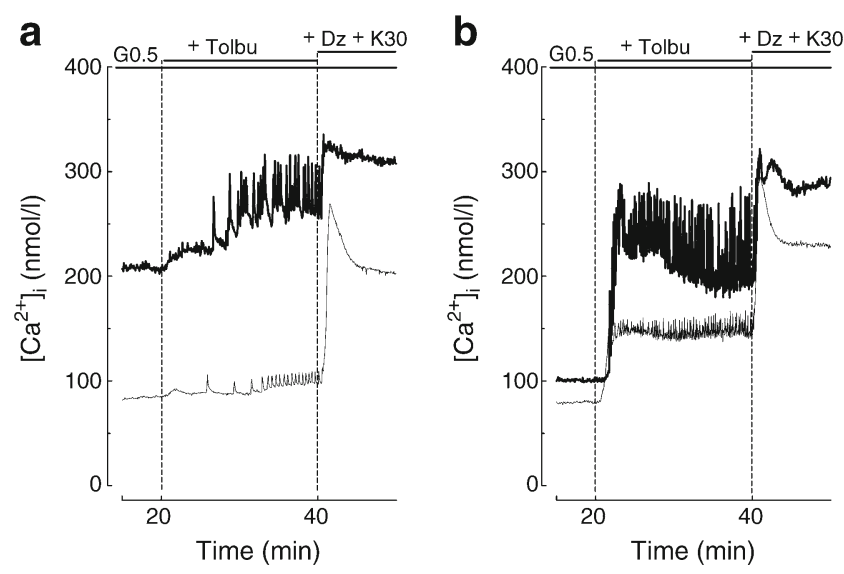

Fig. 4 Effects of MnTBAP on the alterations of tolbutamide-induced $\left[\mathrm{Ca}^{2+}\right]_{\mathrm{i}}$ rise by 1 week of culture in low glucose. Rat islets were cultured for 1 week in the presence of G5 (a) or G10 (b) in the absence (thin traces) or presence (thick traces) of $50 \mu \mathrm{mol} / 1 \mathrm{MnTBAP}$. They were then perifused with a medium containing $0.5 \mathrm{mmol} / 1$ glucose (G0.5) and acutely stimulated with $500 \mu \mathrm{mol} / 1$ tolbutamide (Tolbu), as indicated on top of the panels ( Dz, $250 \mu \mathrm{mol} / 1$ diazoxide; K30, $30 \mathrm{mmol} / 1$ extracellular $\mathrm{K}^{+}$concentration). Shown are traces from individual islets representative of 26-28 islets from three different islet preparations. Mean $\left[\mathrm{Ca}^{2+}\right]_{\mathrm{i}}$ values are shown in Table 6

oxidation in beta cells exposed to low glucose was found to be reduced by rotenone, which inhibits the mitochondrial electron-transport-chain complex I [14, 31]. Nevertheless, because $\mathrm{H}_{2} \mathrm{O}_{2}$ diffuses through lipid membranes, oxidative stress should also occur in the cytoplasm of beta cells exposed to low glucose, as suggested by the increase in expression of oxidative stress-response genes. It is indeed likely that the almost fully reduced state of cytosolic roGFP1 hampered detection of a moderate increase in thiol oxidation in G5 [27]. In this context, it is also interesting to note that NAC was able to reduce the stimulation of Hmoxl and Mt1a mRNA expression by low glucose but did not reduce mt-roGFP1

Table 6 Effects of MnTBAP on changes in islet $\left[\mathrm{Ca}^{2+}\right]_{\mathrm{i}}$ induced by tolbutamide after 1 week of culture in low vs intermediate glucose concentrations

\begin{tabular}{llcll}
\hline Culture condition & $n$ & \multicolumn{2}{l}{$\left[\mathrm{Ca}^{2+}\right]_{\mathrm{i}}(\mathrm{nmol} / \mathrm{l})$} \\
\cline { 2 - 5 } & & $\mathrm{G} 0.5$ & $\Delta(\mathrm{G} 0.5+\mathrm{Tolbu})$ & $\Delta(\mathrm{G} 0.5+\mathrm{K} 30 \mathrm{Dz})$ \\
\hline G5 & 26 & $87 \pm 2^{*}$ & $17 \pm 3^{*}$ & $121 \pm 1^{*}$ \\
G5+MnTBAP & 28 & $190 \pm 9^{*}, \dagger$ & $70 \pm 4^{*, \dagger}$ & $117 \pm 4^{*}$ \\
G10 & 26 & $79 \pm 1$ & $75 \pm 5$ & $179 \pm 6$ \\
G10+MnTBAP & 26 & $105 \pm 3^{\dagger}$ & $128 \pm 5^{\dagger}$ & $213 \pm 8^{\dagger}$ \\
\hline
\end{tabular}

Results are means \pm SEM for the indicated number of experiments $(n)$ In each experiment illustrated in Fig. 4, we calculated the mean $\left[\mathrm{Ca}^{2+}\right]_{\mathrm{i}}$ during the first $4 \mathrm{~min}$ in $\mathrm{G} 0.5$, the last $10 \mathrm{~min}$ in G0.5+Tolbu, and the last $5 \mathrm{~min}$ in $\mathrm{G} 0.5+\mathrm{K} 30 \mathrm{Dz}$

${ }^{*} p<0.05$ for the effect of glucose (G5 vs G10) and $\dagger p<0.05$ for the effect of MnTBAP by two-way ANOVA + Bonferroni correction

Dz, diazoxide; Tolbu, tolbutamide 
oxidation and beta cell apoptosis. This lack of efficacy of NAC, which has also been observed in INS-1 cells exposed to low glucose [31], may result from its inability to reach the mitochondrial compartment or the nature of the reactive species involved.

Role of oxidative stress in the loss of GSIS after culture in low glucose The almost complete loss of GSIS in islets chronically cultured in low glucose is unlikely to have resulted from the $\sim 10 \%$ reduction in beta cell proportion in the islets. It rather resulted from the combination of an $\sim 50 \%$ reduction in the glucose stimulation of mitochondrial metabolism, an $\sim 70 \%$ decrease in insulin content, an $\sim 90 \%$ decrease in glucose-induced $\left[\mathrm{Ca}^{2+}\right]_{\mathrm{i}}$ rise, and an $\sim 98 \%$ reduction in $\mathrm{Ca}^{2}$ ${ }^{+}$-induced insulin secretion. The reduction in the glucose stimulation of mitochondrial metabolism was relatively small, indicating that it better resisted prolonged culture in G5 than other stimulus-secretion coupling events. It may, however, contribute to the loss of GSIS after culture in G5, as it lies upstream of the glucose stimulation of $\mathrm{Ca}^{2+}$ influx, $\mathrm{Ca}^{2+}$. induced exocytosis and insulin synthesis $[34,35]$. However, the strongly reduced $\mathrm{Ca}^{2+}$ response to tolbutamide after culture in G5 indicates that the coupling between mitochondrial metabolism and $\mathrm{Ca}^{2+}$ influx was markedly altered in these islets, as was the coupling between $\mathrm{K} 30$-induced $\left[\mathrm{Ca}^{2+}\right]_{\mathrm{i}}$ rise and insulin secretion. The latter two defects thus mainly contribute to the loss of GSIS after prolonged culture in G5.

Interestingly, reducing mitochondrial oxidative stress and apoptosis by $50-70 \%$ with MnTBAP did not improve the acute glucose stimulation of $\mathrm{NAD}(\mathrm{P}) \mathrm{H}$ production, mitochondrial membrane hyperpolarisation and ATP production, and only tended to increase insulin mRNA levels, islet insulin content and stimulation of insulin secretion by glucose and K30. It therefore seems that these alterations may have resulted from the lack of glucose per se independently of an increase in mitochondrial oxidative stress. Culture in G5 is indeed associated with decreased expression of many genes that are enriched in beta cells and are involved in the maintenance of their glucose responsiveness [1, 8]. However, one cannot totally exclude the possibility that these functional alterations resulted from their exquisite sensitivity to the lower level of oxidative stress that persists in the presence of MnTBAP, or from the presence of ROS against which MnTBAP is ineffective. Indeed, among the transcription factors that govern beta cell-specific gene expression, MAF-A and PDX-1 have been shown to be highly sensitive to oxidative stress [36, 37]. Mitochondrial metabolism is also highly susceptible to oxidative stress [38], in part because of S-glutathiolation and consequent inhibition of mitochondrial complex I and IV, aconitase and pyruvate dehydrogenase [39]. Finally, several components of the exocytotic machinery, including $N$-ethylmaleimide-sensitive factor and SNAP25, are highly sensitive to oxidative stress, leading to a marked reduction in SNARE complex formation upon $\mathrm{H}_{2} \mathrm{O}_{2}$ treatment in other cell types [40, 41].

In contrast, MnTBAP significantly improved the stimulation of $\mathrm{Ca}^{2+}$ influx by glucose, indicating that it is oxidative stress that specifically alters the coupling between mitochondrial metabolism and $\mathrm{Ca}^{2+}$ influx after culture in G5, as reported in clonal insulin-secreting INS-1 cells exposed to exogenous $\mathrm{H}_{2} \mathrm{O}_{2}$ [42]. Such uncoupling is unlikely to have resulted from large alterations in voltage-dependent $\mathrm{Ca}^{2+}$ channels, as shown by the normal rise in $\left[\mathrm{Ca}^{2+}\right]_{\mathrm{i}}$ upon membrane depolarisation with $\mathrm{K} 30$. It may rather result from subtle alterations in their voltage sensitivity, alterations in ATP-sensitive $\mathrm{K}^{+}$channel $\left(\mathrm{K}_{\text {ATP }}\right.$ channel) properties [43, 44], or increased expression/activity of a repolarising current, e.g. the large conductance $\mathrm{Ca}^{2+}$-activated $\mathrm{K}^{+}$channels [45]. The last two hypotheses (altered $\mathrm{K}_{\mathrm{ATP}}$ channel properties and increased repolarising current) are supported by the observation that MnTBAP markedly improved the acute $\left[\mathrm{Ca}^{2+}\right]_{\mathrm{i}}$ rise in response to a maximal concentration of tolbutamide. However, these results do not allow us to distinguish between the two hypotheses.

The pathophysiological relevance of this study is not likely to be restricted to the rare instances when normal beta cells are exposed to sustained hypoglycaemia because of the presence of a focal insulinoma. Indeed, the changes in islet gene expression and beta cell survival observed after culture in low glucose have also been described under conditions associated with a decrease in the glucose sensitivity of beta cells, i.e. after in vitro treatment with cytokines, $\mathrm{H}_{2} \mathrm{O}_{2}$ and ribose, or in islets isolated from rodent models of type 1 and type 2 diabetes (reviewed by Martens and van de Casteele [16] and Jonas et al [46]). Interestingly, it has recently been shown that increasing glucose metabolism with a glucokinase activator partially protects beta cells from $\mathrm{H}_{2} \mathrm{O}_{2}$-induced apoptosis in vitro [47].

In conclusion, MnTBAP efficiently decreases mitochondrial glutathione oxidation and islet cell apoptosis during prolonged culture in low glucose without significantly improving GSIS, indicating that mitochondrial oxidative stress contributes differently to islet cell apoptosis and insulin secretory defects under these conditions. Regarding drug development, targeting beta cell survival may not suffice to restore insulin secretion when beta cells suffer from prolonged mitochondrial oxidative stress, e.g. when glucose metabolism is reduced.

Acknowledgements We thank D. Charlier and F. Knockaert (Université catholique de Louvain) for expert technical help and P. Gilon (Pôle d'endocrinologie, diabète et nutrition, Institut de recherche expérimentale et clinique, Université catholique de Louvain) for helpful comments on the manuscript. We also thank P. Henriet (Cell Unit, de Duve Institute, Université catholique de Louvain) for access to his microplate luminometer. 
Funding This work was supported by Grants 3.4516.09 from the Fonds de la Recherche Scientifique Médicale (Belgium), the Fonds Spécial de Recherche from Université catholique de Louvain, the Interuniversity Poles of Attraction Program (P6/40)-Belgian Science Policy, and the Société Francophone du Diabète. J. Duprez is the recipient of a FRIA fellowship, and J.-C. Jonas is Research Director of the Fonds de la Recherche Scientifique-FNRS (Belgium).

Duality of interest The authors declare that there is no duality of interest associated with this manuscript.

Contribution statement SMP, LPR and JCJ conceived and designed the study; all authors made substantial contributions to acquisition, analysis, and interpretation of data; SMP and LPR drafted the paper, JD made significant corrections/suggestions to the paper, JCJ wrote the final version of the paper. All authors approved the final version.

\section{References}

1. Hinke SA, Hellemans K, Schuit FC (2004) Plasticity of the $\beta$ cell insulin secretory competence: preparing the pancreatic $\beta$ cell for the next meal. J Physiol 558:369-380

2. Karaca M, Magnan C, Kargar C (2009) Functional pancreatic betacell mass: involvement in type 2 diabetes and therapeutic intervention. Diabetes Metab 35:77-84

3. Burch PT, Trus MD, Berner DK, Leontire A, Zawalich KC, Matschinsky FM (1981) Adaptation of glycolytic enzymes: glucose use and insulin release in rat pancreatic islets during fasting and refeeding. Diabetes 30:923-928

4. Chen L, Komiya I, Inman L et al (1989) Effects of hypoglycemia and prolonged fasting on insulin and glucagon gene expression. Studies with in situ hybridization. J Clin Invest 84:711-714

5. Iwashima Y, Kondoh-Abiko A, Seino S et al (1994) Reduced levels of messenger ribonucleic acid for calcium channel, glucose transporter-2, and glucokinase are associated with alterations in insulin secretion in fasted rats. Endocrinology 135:1010-1017

6. Blume N, Skouv J, Larsson LI, Holst JJ, Madsen OD (1995) Potent inhibitory effects of transplantable rat glucagonomas and insulinomas on the respective endogenous islet cells are associated with pancreatic apoptosis. J Clin Invest 96:2227-2235

7. Schuit F, Flamez D, de Vos A, Pipeleers D (2002) Glucoseregulated gene expression maintaining the glucose-responsive state of $\beta$-cells. Diabetes 51(Suppl 3):S326-S332

8. Bensellam M, van Lommel L, Overbergh L, Schuit FC, Jonas JC (2009) Cluster analysis of rat pancreatic islet gene mRNA levels after culture in low-, intermediate- and high-glucose concentrations. Diabetologia 52:463-476

9. Efanova IB, Zaitsev SV, Zhivotovsky B et al (1998) Glucose and tolbutamide induce apoptosis in pancreatic $\beta$-cells. A process dependent on intracellular $\mathrm{Ca}^{2+}$ concentration. J Biol Chem 273:33501-33507

10. Ling Z, Hannaert JC, Pipeleers D (1994) Effect of nutrients, hormones and serum on survival of rat islet beta cells in culture. Diabetologia 37:15-21

11. Kefas BA, Cai Y, Ling Z et al (2003) AMP-activated protein kinase can induce apoptosis of insulin-producing MIN6 cells through stimulation of c-Jun-N-terminal kinase. J Mol Endocrinol 30:151-161

12. Hoorens A, van de Casteele M, Klöppel G, Pipeleers DG (1996) Glucose promotes survival of rat pancreatic $\beta$ cells by activating synthesis of proteins which suppress a constitutive apoptotic program. J Clin Invest 98:1568-1574

13. Van de Casteele M, Kefas BA, Cai Y et al (2003) Prolonged culture in low glucose induces apoptosis of rat pancreatic $\beta$-cells through induction of c-myc. Biochem Biophys Res Commun 312:937-944

14. Martens GA, Cai Y, Hinke S, Stange G, van de Casteele M, Pipeleers D (2005) Glucose suppresses superoxide generation in metabolically responsive pancreatic $\beta$ cells. J Biol Chem 280:20389-20396

15. Hou N, Torii S, Saito N, Hosaka M, Takeuchi T (2008) Reactive oxygen species-mediated pancreatic $\beta$-cell death is regulated by interactions between stress-activated protein kinases, p38 and cJun N-terminal kinase, and mitogen-activated protein kinase phosphatases. Endocrinology 149:1654-1665

16. Martens GA, van de Casteele M (2007) Glycemic control of apoptosis in the pancreatic beta cell: danger of extremes? Antioxid Redox Signal 9:309-317

17. Konorev EA, Kotamraju S, Zhao H, Kalivendi S, Joseph J, Kalyanaraman B (2002) Paradoxical effects of metalloporphyrins on doxorubicin-induced apoptosis: scavenging of reactive oxygen species versus induction of heme oxygenase-1. Free Radic Biol Med 33:988

18. Batinic-Haberle I, Cuzzocrea S, Reboucas JS et al (2009) Pure MnTBAP selectively scavenges peroxynitrite over superoxide: comparison of pure and commercial MnTBAP samples to MnTE-2-PyP in two models of oxidative stress injury, an SODspecific Escherichia coli model and carrageenan-induced pleurisy. Free Radic Biol Med 46:192-201

19. Roma LP, Duprez J, Takahashi HK, Gilon P, Wiederkehr A, Jonas JC (2012) Dynamic measurements of mitochondrial hydrogen peroxide concentration and glutathione redox state in rat pancreatic $\beta$-cells using ratiometric fluorescent proteins: confounding effects of $\mathrm{pH}$ with HyPer but not roGFP1. Biochem J 441:971-978

20. Khaldi MZ, Guiot Y, Gilon P, Henquin JC, Jonas JC (2004) Increased glucose sensitivity of both triggering and amplifying pathways of insulin secretion in rat islets cultured for one week in high glucose. Am J Physiol Endocrinol Metab 287: E207-E217

21. Jonas JC, Sharma A, Hasenkamp W et al (1999) Chronic hyperglycemia triggers loss of pancreatic $\beta$ cell differentiation in an animal model of diabetes. J Biol Chem 274:14112-14121

22. Pascal SM, Veiga-da-Cunha M, Gilon P, van Schaftingen E, Jonas JC (2010) Effects of fructosamine-3-kinase deficiency on function and survival of mouse pancreatic islets after prolonged culture in high glucose or ribose concentrations. Am J Physiol Endocrinol Metab 298:E586-E596

23. Hanson GT, Aggeler R, Oglesbee D et al (2004) Investigating mitochondrial redox potential with redox-sensitive green fluorescent protein indicators. J Biol Chem 279:13044-13053

24. Detimary P, Jonas JC, Henquin JC (1996) Stable and diffusible pools of nucleotides in pancreatic islet cells. Endocrinology 137:4671-4676

25. Pascal SM, Guiot Y, Pelengaris S, Khan M, Jonas JC (2008) Effects of c-MYC activation on glucose stimulus-secretion coupling events in mouse pancreatic islets. Am J Physiol Endocrinol Metab 295:E92-E102

26. Leggate J, Allain R, Isaac L, Blais BW (2006) Microplate fluorescence assay for the quantification of double stranded DNA using SYBR Green I dye. Biotechnol Lett 28:1587-1594

27. Meyer AJ, Dick TP (2010) Fluorescent protein-based redox probes. Antioxid Redox Signal 13:621-650

28. Bindokas VP, Kuznetsov A, Sreenan S, Polonsky KS, Roe MW, Philipson LH (2003) Visualizing superoxide production in normal and diabetic rat islets of Langerhans. J Biol Chem 278:9796-9801 
29. Lacraz G, Figeac F, Movassat J et al (2009) Diabetic $\beta$-cells can achieve self-protection against oxidative stress through an adaptive up-regulation of their antioxidant defenses. PLoS One 4:e6500

30. Rebelato E, Abdulkader F, Curi R, Carpinelli AR (2011) Control of the intracellular redox state by glucose participates in the insulin secretion mechanism. PLoS One 6:e24507

31. Sarre A, Gabrielli J, Vial G, Leverve XM, AssimacopoulosJeannet F (2012) Reactive oxygen species are produced at low glucose and contribute to the activation of AMPK in insulinsecreting cells. Free Radic Biol Med 52:142-150

32. Lash LH (2005) Role of glutathione transport processes in kidney function. Toxicol Appl Pharmacol 204:329-342

33. Loor G, Kondapalli J, Schriewer JM, Chandel NS, Vanden Hoek TL, Schumacker PT (2010) Menadione triggers cell death through ROS-dependent mechanisms involving PARP activation without requiring apoptosis. Free Radic Biol Med 49:1925-1936

34. Henquin JC, Nenquin M, Ravier MA, Szollosi A (2009) Shortcomings of current models of glucose-induced insulin secretion. Diabetes Obes Metab 11(Suppl 4):168-179

35. Wicksteed B, Alarcon C, Briaud I, Lingohr MK, Rhodes CJ (2003) Glucose-induced translational control of proinsulin biosynthesis is proportional to preproinsulin mRNA levels in islet beta-cells but not regulated via a positive feedback of secreted insulin. J Biol Chem 278:42080-42090

36. Kaneto H, Kajimoto Y, Miyagawa J et al (1999) Beneficial effects of antioxidants in diabetes: possible protection of pancreatic $\beta$-cells against glucose toxicity. Diabetes 48:2398-2406

37. Harmon JS, Stein R, Robertson RP (2005) Oxidative stressmediated, post-translational loss of MafA protein as a contributing mechanism to loss of insulin gene expression in glucotoxic beta cells. J Biol Chem 280:11107-11113

38. Li N, Brun T, Cnop M, Cunha DA, Eizirik DL, Maechler P (2009) Transient oxidative stress damages mitochondrial machinery inducing persistent $\beta$-cell dysfunction. J Biol Chem 284:2360223612

39. Garcia J, Han D, Sancheti H, Yap LP, Kaplowitz N, Cadenas E (2010) Regulation of mitochondrial glutathione redox status and protein glutathionylation by respiratory substrates. J Biol Chem 285:39646-39654

40. Giniatullin AR, Darios F, Shakirzyanova A, Davletov B, Giniatullin R (2006) SNAP25 is a pre-synaptic target for the depressant action of reactive oxygen species on transmitter release. J Neurochem 98:1789-1797

41. Lowenstein CJ, Tsuda H (2006) N-Ethylmaleimide-sensitive factor: a redox sensor in exocytosis. Biol Chem 387:1377-1383

42. Maechler P, Jornot L, Wollheim CB (1999) Hydrogen peroxide alters mitochondrial activation and insulin secretion in pancreatic $\beta$ cells. J Biol Chem 274:27905-27913

43. Krippeit-Drews P, Kramer C, Welker S, Lang F, Ammon HP, Drews $\mathrm{G}$ (1999) Interference of $\mathrm{H}_{2} \mathrm{O}_{2}$ with stimulus-secretion coupling in mouse pancreatic $\beta$-cells. J Physiol 514:471-481

44. Avshalumov MV, Chen BT, Koos T, Tepper JM, Rice ME (2005) Endogenous hydrogen peroxide regulates the excitability of midbrain dopamine neurons via ATP-sensitive potassium channels. J Neurosci 25:4222-4231

45. Dufer M, Neye Y, Horth K et al (2011) BK channels affect glucose homeostasis and cell viability of murine pancreatic beta cells. Diabetologia 54:423-432

46. Jonas JC, Bensellam M, Duprez J, Elouil H, Guiot Y, Pascal SM (2009) Glucose regulation of islet stress responses and $\beta$-cell failure in type 2 diabetes. Diabetes Obes Metab 11(Suppl 4):6581

47. Futamura M, Yao J, Li X et al (2012) Chronic treatment with a glucokinase activator delays the onset of hyperglycaemia and preserves beta cell mass in the Zucker diabetic fatty rat. Diabetologia 55:1071-1080 